\title{
Prostorsko načrtovanje na ustavnem sodišču
}

UDK: $711: 342.565 .2$

\author{
Marko Starman \\ Ministrstvo za okolje in prostor \\ marko.starman@gov.si
}

\section{IZVLEČEK}

$Z$ odločbo v začetku leta 2002 je ustavno sodišče razveljavilo celotno pravno ureditev prostorskega načrtovanja. $V$ prispevku sem želel obrazložiti motive sodišča, predvsem pa ugotovitve, ki osvetljujejo proces prostorskega načrtovanja. Prostorsko načrtovanje postaja predvsem pravna kategorija, kjer je ustrezna razdelitev pristojnosti med vejami oblasti ter državo in lokalno skupnostjo odločilna za delovanje sistema. Ekonomska analiza prava nam pri tem nudi metodološko pomoč pri razumevanju obnašanja sodišča ter ostalih deležnikov v postopku prostorskega načrtovanja in urejanja prostora nasploh.

Ključne besede: prostorsko načrtovanje, ustavno sodišče, varstvo kmetijskih zemljišč, zdravo življenjsko okolje, pravica do zasebne lastnine.

\section{Kaj je prostorsko načrtovanje - ekonomska analiza}

Ekonomska analiza prava je oblikovala metodologijo za presojo ekonomske učinkovitosti pravnih instrumentov. Ker izhaja iz ekonomskega aksioma, da se ljudje obnašajo racionalno in stremijo $k$ svojim koristim, je koristna tudi pri razlagi, tako pravnih kot političnih pojavov. Motivacijska struktura, ki je temelj ekonomskim zakonitostim, je dominantna in skupna razlagi obnašanja ljudi in inštitucij. Ločevati moramo dve vrsti uporabe ekonomske analize, ko govorimo o pravu. $\vee$ prvem primeru se pravne predpise analizira z vidika učinkovitosti, kot ga razume ekonomija. Kdaj pravno pravilo ali delovanje inštitucij vzpostavi stanje razdelitve produkcijskih sredstev (resursov), ki je učinkovitejša od stanja brez take ureditve? Povedano z drugimi besedami, iščemo odgovor na vprašanje, kdaj pravni sistem vzpostavlja učinkovito razmerje ekonomskih faktorjev? $\vee$ drugem primeru pa uporaba ekonomskih instrumentov služi razlagi 


\section{Marko Starman}

\section{Prostorsko načrtovanje na ustavnem sodišču}

pravnih institutov, in sicer temu, kako ekonomski motivi nosilcev (oblastnega) odločanja vplivajo na sprejemanje oblastnih odločitev. Skratka, ekonomske instrumente se uporablja za analizo delovanja pravnih institucij. Povedano drugače, ali institucije delujejo učinkovito v smeri politično željenih ciljev.

Moramo pa upoštevati, da v Sloveniji trajnost določenih »tržnih anomalij« močno popači izhodiščno stanje ${ }^{1}$. Status quo še vedno ohranja izrazit prepad med zapisanim in dejanskim, med normativnim in prakso ${ }^{2}$. $V$ takem sistemu je težko govoriti o avtonomiji prava. Metodološki pristop je zato kompleksnejši in nekatera izhodišča, ki veljajo $v$ tradicionalnem tržnem gospodarstvu in zrelih demokracijah, niso vedno uporabna za razumevanje tranzicijskih pojavov.

$\checkmark$ primeru prostorskega načrtovanja so instrumenti ekonomske analize prava dejansko priročni. Z instrumenti ekonomske analize lahko ocenimo, kako poteka politični proces, v katerem nastaja prostorsko načrtovanje in hkrati, ali in koliko prostorsko načrtovanje prispeva k zmanjšanju družbenih stroškov. ${ }^{3}$

William A. Fischel predstavi $v$ svoji knjigi Ekonomska analiza pravne ureditve prostorskega načrtovanja tezo, da je prostorsko načrtovanje oziroma določanje namembnosti zemljišč oblika lastninskega upravičenja skupnosti. ${ }^{4}$ Ugotavlja, da je prostorsko načrtovanje predvsem politični proces ${ }^{\mathbf{5}}$ in je zato odločilno za njegovo razumevanje, prav razumevanje, kdo ga obvladuje. Zato je temeljno empirično vprašanje, $v$ čigavem interesu se sprejemajo odločitve,

$1 \mathrm{~V}$ zadnjih letih se je izoblikoval politično-ekonomski pojem "ujete država - state capture». Pojem, ki razlaga stanje, ko so državne institucije le servis edine interesne skupine. In ta servilni odnos ostane tudi, če se politični vrh po volitvah zamenja. Teorije o koruptivni dejavnostih oz. o organiziranem kriminalu na zakonitih tržiščih iz gospodarskih razmer z dolgoletno tržno tradicijo niso ustrezne. Ekonomski resursi kartela, ki so usmerjeni v nevtralizacijo potencialnih konkurentov na tržišču, so zelo visoki in vključujejo nasilje. Potencialni konkurenti na trgu se $v$ teh sistemih lahko učinkovito uprejo po sodnih in drugih pravnih poteh. Prav tako so vir informacij za represivni del državne uprave, ki se spopada s takimi pojavi na civilnem in kazenskem področju. Če potencialni konkurenti nimajo učinkovitega načina in ekonomskega motiva, če ni tradicije svobodne podjetniške pobude, če neodvisna enotna strokovna javnosti ne sili politike $v$ zavračanje prakse projektov, napisane na kožo interesnim skupinam, se taka vprašanja kljub akutnosti preprosto ne odpirajo. Kjer ni tožnika, ni sodnika.

2 Tudi to izhaja iz pojmovnega sveta 70-ih let. Samoupravni dogovorni sistem je umetno ustvaril nov pojmovni svet. $\mathrm{S}$ tem je še dodatno zarezal razkorak med "teorijo" in prakso, med besedo in dejanjem.

3 Družbeni strošek je zmanjšanje bogastva celotne skupnosti. (S prerazporeditvijo uporabe resursov, ki je manj učinkovita kot prejšnja. Zasebni strošek pomeni le prerazporeditev bogastva iz ene osebe na drugo).

4 Poslužuje se dveh ekonomskih pristopov, in sicer na eni strani Coaseo-vega teorema, ki govori o pomenu transakcijskih stroškov, na drugi pa Pigovian-ove analize, kdaj in kje tržni mehanizmi ne delujejo.

5 Podrobna analiza delovanja procesa prostorskega načrtovanja v Sloveniji ni predmet tega prispevka, vsekakor pa se prav iz argumentov, ki jih je ustavno sodišče uporabilo v svojih odločitvah, da $v$ določeni meri razbrati dinamiko prostorskega načrtovanja. 


\section{Marko Starman
Prostorsko načrtovanje na ustavnem sodišču}

kako se te odločitve oblikujejo in nenazadnje, kakšen učinek imajo odločitve na skupnost.

Večja kot je odzivnost političnega procesa na preference neposredno prizadetih, bolj je proces demokratičen. Empirično dokazljivo je, da $\vee$ manjših skupnostih lažje pride do izraza volja večine prebivalstva, kar na eni strani pomeni večjo ekonomsko učinkovitost, na drugi pa nevarnost posega $v$ vitalne interese politično nevplivnih (marginalnih) skupin.

$\checkmark$ kolikor gre za večje enote javne oblasti, obstaja nevarnost, da prevladajo ozke, dobro organizirane interesne skupine in se s tem izničijo interesi širše skupnosti. $\vee$ procesu imajo svoj vpliv prav zaradi visokih transakcijskih ${ }^{\boldsymbol{6}}$ stroškov postopka, ki vključujejo strokovne podlage, javne razgrnitve, predhodne dogovore z lastniki itd., tudi drugi, če navedem le nekatere npr. načrtovalska stroka, avtonomni interes državne ali lokalne birokracije, finančni interesi EU ...

Slovenska praksa zelo očitno povzroča situacijo, da urbanizem sledi lastništvu in da konkurenca med investitorji na istem območju preprosto ni mogoča. Popolnoma jasno je, da je trajna določitev namembnosti zemljišč, ki je vnaprej neodvisna od konkretnih investicijskih namer, sistemski pogoj, da do konkurence lahko sploh pride ${ }^{\mathbf{7}}$ in z njo koristi potrošnikom.

Zakaj je celovitost in dolgoročnost pri načrtovanju tako pomembna, se da preprosto razložiti. Ekonomsko pravno gledano je določitev namembnosti zemljišča opredelitev lastninskih upravičenj in s tem tudi njegove vrednosti. Vrednost

6 R. H. Coase je opredelil pojem transakcijskih stroškov kot sredstvo za razlago ovir pri učinkovitem razporejanju resursov na trgu. Transakcijske stroške se da shematsko opredeliti kot stroške:

- $\quad$ s proizvodnjo in iskanjem informacij,

s pogajanjem in sprejemanjem odločitev,

z izvrševanjem in nadzorom.

7 Ljubljana že več kot 25 let nima celovite urbanistične ureditve, temveč s pomočjo države parcialno, razdrobljeno in nejasno umešča objekte $v$ prostor. Zato se vse skupaj začne in konča na nivoju izdaje gradbenega dovoljenja in je prepuščeno diskreciji državne in občinske administracije. Če situacijo $v$ Ljubljani primerjamo z situacijo $v$ Mariboru, je zelo hitro jasno, kaj pravzaprav ta labirint pomeni. $V$ Mariboru se je $v$ zadnjih letih načrtovalo celoviteje, cene stanovanj so bistveno nižje. Profitne najemnine so nižje od t.i. normiranih neprofitnih najemnin in primanjkljaja stanovanj pravzaprav ni. Res je, da je kupna moč v Mariboru toliko nižja, kar po eni strani pomeni, da je potreba po posebnih subvencioniranih - "socialnih" stanovanjih večja, hkrati pa pomeni tudi to, da je finančni interes interesnih skupin v vzdrževanju labirinta bistveno nižji, kot je to $v$ Ljubljani. Finski primer je popolnoma nekaj drugega. Načrtuje se za obdobje do 2050, in sicer za širšo helsinško pokrajino, s ciljem znižati cene stanovanj, in to tako, da se pridobi 70 milijonov kvadratnih metrov namenjenih stanovanjskim površinam. Gre za odprt, dolgoročen način načrtovanja z odločno intervencijo tako mestnih kot državnih oblasti. Skratka, popolnoma jasno je, da je dolgoročna vizija stvar javnega interesa, to pomeni politike ob objektivno merljivih strokovnih okvirih. 


\section{Marko Starman}

\section{Prostorsko načrtovanje na ustavnem sodišču}

zemljišča je namreč diskontirana vrednost bodočih donosov. Določanje namembnosti zemljišča pomeni izvajanje regulatorne funkcije javne oblasti. Gre za "monopolno" dejavnost. Prostor je naravni monopol, zato ga pravo obravnava kot javno dobro ${ }^{\mathbf{8}}$. Prostorsko načrtovanje je zato upravičeno le kot javna služba.

Naša praksa prostorskega načrtovanja na občinski ravni, prav zaradi odsotnosti celovitega načrtovanja, sledi interesom tistih, ki dejansko razpolagajo z zemljišči na strateških lokacijah. Zato je glavna operacija pridobiti zemljišča, katerih namembnost se bo spremenila tako, da bo njihova cena zrasla. Če gre le za špekulacijo (igro na srečo), sama po sebi ekonomsko ni škodljiva, saj tveganje nosi špekulant. Situacija pa je drugačna, v kolikor obstaja povezava med potencialnim upravičencem zemljišča in organom, ki določa namembnost zemljišča. Nivoji vzajemne odvisnosti in vpliva so lahko različni. V vsakem primeru gre vsaj za obliko trgovanja z notranjimi informacijami, skratka, » insiderstvo ".

Tak proces, poleg jasnih, načelno pravnih pomanjkljivosti, in sicer $v$ smislu neenakosti pred zakonom in pogoste zlorabe javnih pooblastil, je po definiciji ekonomsko neučinkovit. Razdelitev resursov, do katerih pripelje ta proces, pomeni po eni strani uzurpacijo javnega dobra, kot je prostor, po drugi strani pa grobo prerazporejanje sredstev med neorganizirano široko skupino lastnikov manjših zemljišč in potrošnikov ter ožjo interesno skupino, ki nadzoruje politični proces.

Podobno se dogaja tudi pri državnem prostorskem načrtovanju. O kakršnikoli celovitosti in kvalitativnem nadzoru strokovne javnosti je težko govoriti, saj so običajno realne možnosti vrednotenja variantnih rešitev zanemarljive. Iskanje variantnih rešitev ne poteka na odprtem natečaju, na katerem bi neodvisni projektanti konkurirali ${ }^{\mathbf{9}}$, temveč jih pripravi projektant, ki je $v$ službi izvajalca. Zato se tudi državno prostorsko načrtovanje izvaja na majhnih odsekih, ki sledijo drug drugemu in prvi determinira naslednjega, ali obratno.

8 Posner na primeru črpanja nafte in zemeljskega plina utemeljuje ekonomsko upravičenost prisilne koordinacije - intervencijo javne oblasti. Saj vsi lastniki zemljišč črpajo iz istega vira. Vsak izmed njih je motiviran črpati čim več in čim hitreje. S tem nastajajo družbeni stroški in neupravičeno hitro izčrpavanje naravnega bogastva. St. 63, Richard Posner "Economic analysis of Law" Boston, Toronto, London 1992.

9 Kot je jasno iz finskega primera, je konkurenco potrebno vzpostaviti na nivoju zamisli, kajti le tako lahko pridemo do najsodobnejših med drugim tudi tehnoloških rešitev. Primer odseka avtoceste Čebulovica je poučen. Ker glavni izvajalec v tistem času ni bil še tehnološko usposobljen za izvedbo takih predorov, je na tem odseku z bistveno večjimi stroški zgradil odsek z vkopavanjem v hrib. Celo tehnologija, ne le projekt, je bila prilagojena izvajalcu. Ob tem so nastali še dodatni stroški, vključno s spremembami klime na Krasu in meglo na Primorskem. 


\section{Marko Starman
Prostorsko načrtovanje na ustavnem sodišču}

Transakcijski stroški razdrobljene večine, ki v tem procesu izgublja, so tako visoki, da se ni sposobna organizirati v učinkovito interesno skupino, ki bi lahko s pomočjo političnih vzvodov spremenila situacijo. Tudi domet uspešno organiziranih interesnih skupin prizadetih je minimalen, ker so omejeni na svoj ozki interes in se ne morejo širše organizirati. Ponekod je to celo v interesu izvajalca, ki lahko dvigne ceno, ali poveča svoj vpliv s tem, da »reši problem « v zasebno-pravnem odnosu.

\section{Vloga ustavnega sodišča}

Ali je ustavno-sodna veja oblasti lahko institucija, ki se reši "labirinta « ${ }^{\mathbf{1 0}}$ in vzpostavi novo ravnotežje $\vee$ demokratičnem procesu? Ali pa je tudi ustavno sodišče, prav nasprotno, instrument dobro organiziranih interesnih skupin?

Pomen sodne presoje ustavnosti predpisov je že stoletja predmet znanstvenega diskurza in političnih razprav. $\vee$ drugi polovici 70-ih let je, izhajajoč iz prakse ZDA" ${ }^{11}$, prevladala teza, da sodna oblast krepi demokratičnost političnega procesa s tem, da odpravlja njegove ovire in anomalije. Le-te predstavljajo organizirane interesne skupine, ki pod krinko interesov večine prerazporejajo družbeno bogastvo.

Razširjenost ustavno-sodne presoje in sodni aktivizem v t. i. novih demokracijah sta bila $\vee$ zadnjem času deležna posebne pozornosti. Različni avtorji ${ }^{\mathbf{1 2}}$ primerjalnega prava ugotavljajo, da je simptom razširjenosti ustavnih sodišč s širokimi pristojnostmi $\vee$ novih demokracijah po vsem svetu moč razložiti tudi v luči »bitke" med politično dominantnimi interesnimi skupinami. Kaže, da je vzorec dokaj predvidljiv, in sicer $v$ demokracijah, kjer je politični vpliv razpršen,

10 Dr. Marko Kranjc je uporabil ta izraz na 17. posvetu o poslovanju z nepremičninami, ko je govoril o vlogi države pri stanovanjski oskrbi. Dr. Kranjc je tudi avtor gradiva "Platforma za oceno posledic delovanja javnih stanovanjskih skladov na trg in cene nepremičnin, 30 . 11. 2006" $Z$ analizo situacije, ki izhaja iz podedovanega sistema odnosov na trgu, se strinjam $z$ avtorjem. Se pa ne morem strinjati s predlogom rešitev, saj popoln umik države brez aktivne normalizacije razmer pomeni le dokončni prevzem tržišča s strani že uveljavljenega kartela.

11 John Hart Ely v svojem delu "Democracy and Distrust (1980) izvede iz opombe 4. odločitve ameriškega Vrhovnega sodišča v zadevi U. S. v. Caroline Products Co., iz leta 1938 poslanstvo ustavno-sodne presoje ustavnosti, in sicer kot varuha pravic manjšin pred politično dominantno večino.

12 Tom Ginsburg, Judicial Review in New Democracies: Constitutional Courts in Asian Cases, Cambridge University Press, 2003, Ran Hirschl, Towards Juristocracy: The Origins and Consequences of the New Constitutionalism, First Harvard University Press, 2007, Francisco Ramos Romeu, The Establishment of Constitutional Courts: A Study of 128 Democratic Constitutions. 


\section{Marko Starman}

\section{Prostorsko načrtovanje na ustavnem sodišču}

se ustanavljajo močna ustavna sodišča, saj oblastna elita želi preko sodišča ohraniti svoj vpliv tudi v času, ko ne bo več na oblasti. Ustavna sodišča pa so šibka $\vee$ demokracijah, kjer dalj časa dominira ena politična opcija.

Slovensko ustavno sodišče (v nadaljevanju sodišče) je 14. 02. 2002 ob odločanju o ustavnosti in zakonitosti Odloka o spremembah in dopolnitvah odloka o prostorskih in ureditvenih pogojih za plansko celoto č6 za Stanežiče Vižmarje in Odloka o spremembah in dopolnitvah o dolgoročnega plana občin in mesta Ljubljane za obdobje 1986 - 2000 (v nadaljevanju odločba Stanežiče Vižmarje), razveljavilo še Zakon o urejanju naselij in drugih posegov $v$ prostor in Zakon o urejanju prostora $v$ celoti.

Razveljavitev celotne zakonske podlage določenega področja urejanja javnih zadev je pomemben poseg $v$ državno ureditev. Sodišče se je namreč vrsto let soočalo s predpisi o urejanju prostora. Poročilo o delu ustavnega sodišča za leto $1999^{\mathbf{1 3}} \mathrm{npr}$. izpostavlja prav neizvršitev odločbe, s katero je bil odpravljen 10. člen Odloka o spremembah in dopolnitvah prostorskih sestavin plana občine Žalec. V poročilu opozarja na zaskrbljujoč odnos javnosti, vključno s strokovno javnostjo, ki se ne postavi dovolj odločno $v$ bran učinkovitosti sodišča. V Poročilu o delu ustavnega sodišča za leto $2001^{\mathbf{1 4}}$ pa sodišče zakonodajo o urejanju prostora opredeli kot pravno področje, ki bi moralo biti usklajeno z novo ustavno ureditvijo že do konca leta 1993 na podlagi prvega odstavka 1. člena Ustavnega zakona za izvedbo Ustave ter napove začetek postopka za oceno ustavnosti Zakona o urejanju prostora in Zakona o urejanju naselij in drugih posegov $v$ prostor.

Za osvetlitev vprašanja, kaj je sodišče pravzaprav storilo in zakaj je sprejelo tako radikalen ukrep ${ }^{\mathbf{1 5}}$, želim predstaviti nekaj razlag, ki izhajajo iz ekonomske analize prava ${ }^{\mathbf{1 6}}$.

13 Poročilo o delu Ustavnega sodišča za leto 1999, št. Su - 109/99, z dne 20. 12. 1999.

14 Poročilo o delu Ustavnega sodišča Republike Slovenija za leto 2001, z dne 18. 12. 2001.

$15 \mathrm{Iz}$ odločbe izhaja, da vlada $\mathrm{s}$ tem, ko je že predlagala nov Zakon o urejanju prostora $v$ sprejem državnemu zboru, implicitno soglaša z neprimernostjo obstoječe ureditve. Zato je težko govoriti o tem, da je s tem ustavno sodišče radikalno poseglo v razmerja delitve oblasti, ki bi lahko pomenila trenja med nosilci oblasti.

16 R. H. Coase, The Firm the Market and the Law; The University of Chicago Press, 1988; stran 3: "Če so teorije, ki jih je izdelala ekonomska znanost (to vsekakor velja za mikroekonomijo) v glavnem način, kako analizirati opredeljitelje človekovega odločanja (misli, da je temu tako), je enostavno uvideti njihovo uporabnost, ko gre za odločitve $v$ drugih človekovih dejavnostih, kot so politika in pravo". Normativni Coasev-nauk glasi: "Pravo moraš strukturirati tako, da odstraniš ovire učinkovitemu dogovarjanju." Pomen Coase-ove teorije je predvsem $v$ opredelitvi analitičnega pomena t. i. transakcijskih stroškov. 


\section{Marko Starman
Prostorsko načrtovanje na ustavnem sodišču}

- Sodišče preprosto ni imelo več na voljo instrumentov, s katerimi bi lahko učinkovito ${ }^{17}$ skrbelo za zakonitost na pravnem področju. Strošek (transakcijski $^{\mathbf{1 8}}$ ) varovanja zakonitosti je postal tako visok, da je odtehtal koristi sodnega početja. Odločitev je zato racionalna in $v$ skladu s funkcijo, $\mathrm{ki}$ jo opravlja ustavno-sodna oblast.

- Sodišče je na področju varstva ustavnosti in zakonitosti izključno pristojno sodišče in ima zato monopolno jurisdikcijo. Tudi sodna oblast kot institucija maksimira ${ }^{\mathbf{1 9}}$ svoje koristi, med katerimi je tudi oblast. $\mathrm{S}$ to odločbo je okrepilo svoj položaj $v$ sistemu delitve oblasti, tako neposredno z aktom razveljavitve, kot posredno z deklaracijo, zakaj je sistem neustaven.

- Sodišče je sredstvo »interesnih skupin, organiziranih na državni ravni« oz. instrument centralizacije. Z odločbo odpravi zadnjo oviro, ki jo predstavljajo nosilci razpršene politike, in sicer občinske oblasti in posamični interesi poslancev. Verjetnost, da vladni zakonodajni predlog (ZUreP-1) državni zbor sprejme, se je namreč bistveno povečala, saj je grozila pravna praznina in s tem nezmožnost sprejemanja ali spreminjanja prostorskih načrtov.

$\checkmark$ nadaljevanju želim opozoriti na to, kaj se da razbrati iz odločbe same in kaj izhaja iz druge sodne prakse, ki je bila izoblikovana pred in tudi po sprejemu Odločbe U-I-227/00 - Stanežiče - Vižmarje.

17 Npr. Zakon o lokalni samoupravi (UL RS, št. 72/93 s spremembami), je ustavnemu sodišču določil pristojnost odločati o zakonitosti sklepa DZ, s katerim ugotovi, da niso izpolnjeni pogoji za ustanovitev občine ali spremembe njenega območja. Ustavno sodišče je z odločbo (U-I-2/06) zaščitilo svojo učinkovitost in razveljavilo to določbo. Ob tem (20. odst.) ugotavlja, da ustava "zakonodajalcev ne pooblašča, da lahko nekritično širijo pristojnosti ustavnega sodišča" in nadaljuje: "Morebitne dodatne pristojnosti ustavnega sodišča mora določiti tako, da ohranja konsistenten pravni sistem in ne sme posegati v položaj ustavnega sodišča $v$ celotnem pravnem sistemu $v$ razmerju do zakonodajne, izvršilne in sodne veje oblasti."

18 Med transakcijske stroške sodijo tudi stroški z izvrševanjem in nadzorom.

19 Maksimiranje oblasti, vpliva, ugleda je pri sodni oblasti nekoliko specifično in to $v$ kontinetalni Evropi še morda nekoliko bolj kot $v$ anglo-ameriški tradiciji, $v$ primerjavi z maksimiranjem oblasti predstavnikov političnih vej oblasti (poslanci, ministri, predsednik republike). To izhaja iz pojmovanja sodne funkcije, kot "nevtralne" oblasti, zavite v "tančico". Ta tančica ima namen znižati stroške legitimiranja oblasti. To pa ne spremeni temeljne motivacije posameznika. 


\section{Marko Starman}

\section{Prostorsko načrtovanje na ustavnem sodišču}

\subsection{Odločba U-I-227/00 - Stanežiče - Vižmarje ${ }^{20}$}

Najprej se sodišče dotakne vprašanja razmerja med vlado in državnim zborom v zvezi s skrbjo za zakonitost občinskih prostorskih aktov. Ob tem ugotavlja, da zakonska ureditev, ki je bila sprejeta $v$ času veljavnega komunalnega sistema po naravi stvari ne more delovati, saj so določbe, ki vključujejo zakonodajalca $v$ sankcioniranje občin, mrtva črka na papirju ${ }^{21}$. Sodišče ugotavlja, da se je uveljavila praksa, ki jo je legitimiralo sodišče samo ${ }^{\mathbf{2 2}}$, da vlada kot izvršilna veja oblasti vlaga zahteve za razveljavitev oziroma odpravo občinskih prostorskih aktov, za katere meni, da so $v$ nasprotju z državnimi planskimi akti ali drugimi kogentnimi predpisi, pa ne glede na to, ali je o tem pravočasno obvestila občino.

Sodišče še ugotavlja, da so veljavni prostorski predpisi na eni strani prepodrobni, na drugi strani pa omogočajo izjeme, ki so postale pravilo. Skratka, izjemno urejanje prostorskega načrtovanja, ki ga predvidevajo prostorski ureditveni pogoji, je postalo predvsem s spremembo Zakona o urejanju naselij v letu 1997 pravilo. Iz tako nejasne oziroma nesistemske določbe ugotavlja, da se $v$ praksi večina posegov $v$ prostor (izgradnja novih naselij in tudi gradnja industrijskih objektov) izvaja le še s prostorskimi ureditvenimi pogoji.

Sodišče še ugotavlja: "ob velikokrat meglenih in dvoumnih določbah (v) prostorskih ureditvenih pogojih, se je začel prostor dejansko urejati na podlagi lokacijskih dokumentacij, kar je postalo najbolj uporabno orodje prostorskega načrtovanja." Nadalje še ugotavlja, da se občine zavzemajo, da bi imele odločilen vpliv na vsebino lokacijskih dokumentacij, saj se je teža dovoljevanja, tudi izrazito enostranskih investicijskih namer, prenesla prav na ta "strokovni« nivo odločanja. Opozarja še, da se s tem mimo javnosti ter stroke pojavlja nevarnost za prikrito arbitriranje, samovoljo in izigravanja.

Zanimivo je tudi, da sodišče hkrati še izpostavi, da mora sistem omogočati fleksibilnost: "Ukinitev družbene lastnine in s tem seveda zmanjšane možnosti za posege $\vee$ državno lastnino. Uvedba tržnega gospodarstva in poudarek na

20 Novela ZUN je dopolnila 3. odstavek 25. člena z besedami "kakor tudi za gradnje, ki pomenijo zaokrožitev obstoječih gradbenih struktur" in črtala 4. odstavek tega člena.

21 Tudi to ni naključno. Državni zbor je zaradi svoje sestave bolj odziven na konkretne potrebe lokalnih skupnosti kot vladna administracija (za ekonomsko analizo obnašanja poslancev glej Federalism R. P. Inman, D. L. Rubinfield).

22 Ustavno sodišče praviloma ugodi zahtevi vlade. Že dejstvo, da občina ni poslala svojih aktov v mnenje vladi, zadošča za njihovo razveljavitev. 
zasebni iniciativi zahtevajo ne le drugačen, temveč tudi fleksibilnejši pristop $\mathrm{h}$ konkretnemu načrtovanju prostora s prostorskimi izvedbenimi akti. ${ }^{23}$

Sodišče definira "prostor kot naravno bogastvo in nenadomestljivo dobrino." Ob tem pa nalaga državi, da zagotovi takšne pogoje uporabe naravnega bogastva, ki ga bo ohranjala z vidika varstva okolja, kot tudi z vidika njegove krajinske in urbanistične podobe.

Skratka, ugotovi, da je prav zakonodajalec omogočil neustavno stanje, ki pomeni kršitev načela pravne države. Zakonodajalec je vzpostavil normativni sistem, ki omogoča parcialno urejanje prostora in prekomerno diskrecijo tako občinske kot državne birokracije. Sistem prostorskega načrtovanja je izgubil svojo transparentnost, ki jo zagotavlja celovitost načrtovanja, nadzor javnosti, strokovne kot splošne, političnega procesa, $v$ katerem se oblikuje to načrtovanje, omogočil pa je prevlado interesnih skupin s svojimi parcialnimi investicijskimi interesi.

\section{Poskus Sodne definicije prostorskega načrtovanja}

Ustavno sodišče je v zadevi U-I-281/00 (primer Livade II-Izola) definiralo: »Prostorsko planiranje, katerega nosilci so državni organi in organi lokalnih skupnosti, je področje, ki povezuje lastninsko-pravne režime različnih kategorij zemljišč. Prostorski plan z načrtovanjem namenske rabe na posameznih območjih načrtuje tudi pravni režim te ali one kategorije zemljišč. Nosilec planiranja je $v$ veliki meri pri planskih odločitvah svoboden, zlasti pri planiranju poselitve in razmestitve različnih dejavnosti, planiranju infrastrukture itd., hkrati pa je vezan na ustavo in zakone."

Iz tega izhaja, da je domneva zakonitosti na strani nosilca prostorskega načrtovanja, ki izvaja svoja "zakonodajna" pooblastila. Sodišče ima resne težave s testom zakonitosti, zato ga operacionalizira preko druge področne zakonodaje. Opre se na drugi odstavek 71. člena, 44. člen, 72. člen, 33. člena Ustave.

23 Fleksibilnosti pa občinam ne dopušča, saj to pomeni kršitev postopkovnih pravil, ki vključujejo javnost (javno razgrnitev in/ali obravnavo). 


\section{Marko Starman}

\section{Prostorsko načrtovanje na ustavnem sodišču}

\subsection{Varstvo kmetijskih zemljišč (drugi odstavek 71. člena Ustave)}

V primeru Livade II-Izola sodišče ugotavlja, da je »na področju kmetijskih zemljišč tako eden izmed najpomembnejših institutov prav njihovo načrtovanje in varstvo pred spreminjanjem namembnosti«. $V$ sporu med državo in občino je samostojno ocenilo zakonitost odločitev občine. Sodišče se ni sklicevalo na negativno mnenje resornega ministrstva, temveč je samostojno ovrednotilo pravne in dejanske podlage in ugotovilo neupravičenost spremembe kategorije kmetijskega zemljišča. V nekoliko starejšem primeru U-I-153/95 (primer cestnega odseka Depala vas - Črnuče) je sodišče, sklicujoč na pozitivno strokovno ${ }^{24}$ mnenje vlade o dopustnosti posega na varovana kmetijska zemljišča, zavrnilo pobudo prizadetih občanov.

Ko gre za trase cest ${ }^{\mathbf{2 5}}$, se sodišče sistematično izogiba presoji izbire med variantami. Sodišču zadošča, da je ovrednotenih več variantnih rešitev. Že na podlagi nove zakonodaje (ZUreP-1) je sodišče kvalificiralo zahtevo po variantnih rešitvah, ko gre za kmetijska zemljišča, in to ne glede na soglasje pristojnega ministrstva. V primeru U-I-49/04 (golf igrišča $\vee$ Sečovljah) ugotavlja, »da gre za spremembo namembnosti najboljših kmetijskih zemljišč, zato izdelana študija o primerljivosti dveh lokacij ne more biti sama sebi namen ...". Sodišče zato zahteva, da se javno razgrne in javno obravnavata obe variantni rešitvi.

Ko ni ustavno varovanega interesa kmetijskih zemljišč, je pristop sodišča drugačen. $\vee$ primeru skladiščno-transportne cone $\vee$ Toledovi ulici $\vee$ Rušah $^{\mathbf{2 6}}$ sodišče izrecno: "Ustavno sodišče ne more presojati ali je zaradi naravnih in drugih omejitev, tehnoloških zahtev ter pogojev organov, organizacij oz. skupnosti, ki dajejo soglasje k osnutkom teh načrtov, možna le ena rešitev glede predvidenih prostorskih ureditev ..., ker gre za urbanistično in ne pravno presojo."

$24 \mathrm{~V}$ "strokovno utemeljenost razlogov za izbor poteka ceste " se ne more spuščati, zadošča, da je občina izdelala več variant. Glede vprašanja ali je potrebno pripraviti variantne rešitve, če zakon tega ne zahteva brezpogojno, sodišče prepusti to vprašanje t. i. strokovni presoji.

25 U-I-313/04 Po nobeni izmed od nji naj bi se ne moglo povsem izogniti gradnji na najboljših kmetijskih zemljiščih «.Bi to pomenilo, da bi imela prednost, če bi obstajala.

$26(U-I-227 / 97)$ 


\subsection{Pravica do sodelovanja pri upravljanju javnih zadev (44. člen Ustave)}

Ustavno sodišče odpravlja akte, ki niso ustrezno javno razgrnjeni ali javno obravnavani. Neposredno prizadeti prebivalci morajo biti na primeren način obveščeni o javni obravnavi ${ }^{27}$. Po javni razgrnitvi se lahko spreminja le tiste načrtovane posege, ki so bili razgrnjeni in obravnavani. Ne sme pa se dodajati novih načrtovanih posegov ${ }^{\mathbf{2 8}}$. Sodišče pa zahteva le javno obravnavo, podane pripombe morajo biti evidentirane, do njih se je občina ali država dolžna le opredeliti. Glede javnega natečaja, ki predstavlja vključitev strokovne javnosti, sodišče ni strogo in to prepušča strokovni (nepravni) ${ }^{\mathbf{2 9}}$ oceni ali je rešitev vsebinsko in oblikovno takšen poseg, za katerega je predpisan javni natečaj.

Standarda, ki ga zahteva sodišče, ni težko izpolniti. Domneva se, da je javna oblast pravilno vodila postopek. Dokazno breme je na strani pobudnikov. Sodišče pušča $\vee$ enem zadnjih primerov $(U-1-153 / 04)^{30}$, in sicer $\vee$ zadevi »vetrnih elektrarn na Volovji rebri« priprta vrata obravnavi trditev pobudnikov o arbitrarnosti in samovoljnosti vodenja prostorske konference. Sodišče se izogiba presoji konkretnih aktov ${ }^{\mathbf{3 1}}$, kjer obstaja drugo pravno varstvo.

\subsection{Pravica do zdravega življenjskega okolja (72. člen Ustave) - Presoja vplivov na okolje planskih aktov}

Zahteva po pripravi posebnih konkretiziranih strokovnih podlag, ko gre za vplive na okolje ureditvenih načrtov, se uveljavlja že od primera industrijske cone Sermin-Koper ${ }^{32}$. Zadoščalo je, da občina izkaže, da so bile pri pripravi načrta pripravljene zahtevane strokovne podlage. Pogoji in omejitve glede vplivov na okolje določajo izvedbeni predpisi, ki so (predvidoma) upoštevani ${ }^{\mathbf{3 3}} \mathrm{v}$ strokovnih podlagah.

27 U-I-126/93

28 U-I- 298/95, tudi U-I- 220/96

29 Zakon tega ne zahteva brezpogojno, pa vendarle bi lahko sodišče izoblikovalo pravni standard. Zadošča že strokovno mnenje.

30 "Pravica iz 44. člena Ustave je klasična splošna ustavna pravica, katere bistvena značilnost je, da vsem državljanom jamči možnost do sodelovanja pri upravljanju javnih zadev v skladu za zakonom."

31 Tudi v tej ustavni odločbi izrecno zavrne pobudo, da bi presojalo zakonitost sklepa vlade o usklajenosti občinskega akta s predpisi.

32 U-I-130/96

$33 \mathrm{~V}$ primeru skladiščno-transportne cone $\mathrm{v}$ Toledovi ulici v Rušah (odst. 30) 


\section{Marko Starman}

\section{Prostorsko načrtovanje na ustavnem sodišču}

Pravica do zdravega okolja nima samostojne zakonske ureditve, temveč se presoja, glede na mejne vrednosti, ki jih določajo predpisi. Pri presoji odloka o zazidalnem načrtu centralnega območja Radovljice ${ }^{\mathbf{3 4}}$ sodišče navaja: "da se pravica do zdravega okolja varuje s standardi, ki veljajo za gradnjo objektov in normami, ki zagotavljajo, da ne pride do takšnih vplivov na okolje, ki bi bili tako prekomerni, da bi ogrožali zdravje ljudi. « Pobudnik mora zato pokazati, da so škodljivi vplivi prekomerni, ker presegajo predpisane mejne vrednosti.

Sodišče je izoblikovalo načelo, da se pri prostorskih aktih posebno pozornost posveti vplivom, ki jih bodo predvidene dejavnosti imele na sosedna območja in okolja. Ta princip, ki spominja na civilnopravni institut prepovedanih imisij, je ustavno sodišče oblikovalo že z določbo industrijski cone SerminKoper v letu 1997.

Sodišče se je z vprašanjem presoje vplivov na okolje $v$ fazi planskih in izvedbenih prostorskih aktov omejilo, kot povedano, na zahtevo po ustreznih strokovnih podlagah. Konkretna presoja je prepuščena, po zakonu, poročilom o vplivom na okolje v postopku izdaje dovoljenja za poseg v prostor. ${ }^{35}$ Sodišče se dosledno ni spuščalo $\vee$ ocenjevanje posebnih strokovnih podlag o naravnih lastnostih in posebnih strokovnih podlag o ustvarjenih razmerah na območju, saj gre za njihovo strokovno in ne pravno presojo. ${ }^{\mathbf{3 6}}$

$\checkmark$ primeru vetrnih elektrarn na Volovji Rebri pa je pristop drugačen. Pobudniki so izpodbijali planski in izvedbeni akt občine in sicer zato, ker se tako občina kot vlada nista držali smernic Zavoda RS za varstvo narave in Agencije RS za okolje. Vlada je podala pozitivno mnenje na občinski plan in ugotavlja, da je odklonilno mnenje zavoda neupravičeno.

Sodišče svoje odločitve ni formalno oprlo na sklep organa, ki je po zakonu "soglasodajalec", temveč ugotavlja, da so odstopanja od naravovarstvenih smernic utemeljena, izhajajoč iz poročila, ki ga je pripravil pooblaščenec za občino. Dejansko se je sodišče spustilo $v$ konkretno strokovno presojo. $\vee$ tem primeru je imelo celo možnost opreti svojo odločitev na pravni $\operatorname{argument}^{37}$, da

34 Glej opombo U-I-24/96-

$35 \vee$ zadevi garažne hiše (U-I-315/97) ob vstopu v mesto Piran ustavno sodišče opredeli koncept celovite presoje vplivov na okolje, ki ga predvideva novi Zakon o varstvu okolja (ZVO-1) in ga na neki način izenači s tem, kar ustavno sodišče počne, ko presoja vplive na sosednja območja in okolje po ustaljeni sodni praksi. Zanimivo je, da izpostavlja to dvojnost. Dosedanja praksa obravnava vplive na okolje $v$ času sprejemanja prostorskih aktov s pripravo strokovnih podlag. Po novem postopku pa so bo to dogajalo ločeno in samostojno po Direktivi iz leta 2001.

36 Prav tam. (op. 26).

$37 \mathrm{Ki}$ je $\mathbf{v}$ obrazložitvi večkrat omenjen, ni pa temelj odločitve. 


\section{Marko Starman}

za izdelavo odklonilnega mnenja zavod ni imel pravne podlage, ker pravnih temeljev o posebni zaščiti tega območja še ni bilo. Težko si je predstavljati, da bi Ustavno sodišče sistematično arbitriralo med različnimi nasprotujočimi se strokovnimi mnenji. ${ }^{\mathbf{3 8}}$

\subsection{Pravica do zasebne lastnine 33. člen Ustave}

Za razliko od splošnih ustavnih pravic, kot sta pravica iz 44. in 72. člena, je pravica do zasebne lastnine konkretizirana in individualizirana pravica, ki je ustavno-sodno zaščitena $v$ vseh sodobnih liberalno-demokratičnih sistemih.

Vpliv na okolico je moč razumeti tudi kot poseg v lastninsko pravico, zato se argumentaciji iz 72. člena Ustave in 33. člena $\vee$ določeni meri prepletata. Sodišče se je opredelilo ob zatrjevani kršitvi iz 72. člena, in sicer: "ljudje, ki živijo $v$ določeno povezani krajevni skupnosti, morajo nujno trpeti tudi nekatere neprijetnosti, ki so neogibno potrebne zaradi življenja v taki skupnosti... ${ }^{\mathbf{3 9}} \mathrm{V}$ že omenjenem primeru skladiščno-transportne cone ob Toledovi ulici $\vee$ Rušah, kjer pobudnica zaradi vplivov na okolje zatrjuje kršitev 33. člena Ustave, sodišče ugotavlja: "posameznikova svoboda na premoženjskem področju ne more biti neomejena, vezana le na posameznika - lastnika, ampak se morajo pri izvrševanju te pravice upoštevati tudi interesi drugih članov skupnosti." Sodišče nadaljuje, da $\vee$ okviru socialne vezanosti lastninske pravice sodi tudi urbanistično načrtovanje posegov $v$ prostor. $V$ kolikor je le to izpeljano $v$ skladu $z$ zakonom na podlagi ustreznih planskih aktov, so taki posegi $\vee$ lastninsko pravico dopustni.

Odločbe, ki obravnavajo poseg v lastninska upravičenja s prostorskimi akti, sistematično zavračajo argumentacijo lastnikov sosednjih zemljišč ali celo lastnikov zemljišč, ki se urejajo, da z le-temi posegajo $v$ njihovo lastninsko pravico. Sodišče se namreč sklicuje predvsem $v$ zgodnejših odločbah na to, da je le prostorski izvedbeni načrt lahko temelj za razlastitev. Planski akti oziroma prostorski ureditveni pogoji (ki, kot vemo, so najpogostejša oblika za urejanje prostora) namreč ne morejo biti temelj za razlastitev. Sodišče se zato postavi na dokaj formalistično pozicijo. Na eni strani ugotavlja, da se kompleksna gradnja

38 Morda je ta primer specifičen, saj ustavno sodišče sledi tako želji občine kot države. Ne želi si pa umakniti svojega nadzora nad presojo zakonitosti odločitev vlade, ki potrjuje občinske akte.

39 Je zadeva: U-I-24/96. 


\section{Marko Starman}

\section{Prostorsko načrtovanje na ustavnem sodišču}

ureja s PUP-i, po drugi strani pa lastnikom ne nudi lastniško-pravnega varstva, ko ta akt posega $v$ njihovo lastniško upravičenje. ${ }^{\mathbf{4 0}}$

\section{Kako razumeti sodno početje}

Iz sodne prakse, ki se je izoblikovala do sprejema odločbe StanežičeVižmarje o razveljavitvi celotnega pravnega področja, izhaja, da sodišče definira postopek prostorskega načrtovanja kot relativno svobodno pristojnost lokalne samouprave ${ }^{\mathbf{4 1}}$ pri razmeščanju dejavnosti na svojem območju. Istočasno pa izvrševanje tega lastninskega upravičenja omejuje. Kot nosilca omejevanja sodišče pretežno priznava državno oblast. Praviloma ugodi zahtevam vlade. Redno sledi vladnim stališčem in to utemeljuje z argumentom, da prostorsko načrtovanje učinkuje tudi preko meja posamične občine.

Sodišče sistematično spodbuja participacijo lokalno organiziranih interesnih skupin in le izjemoma nacionalnih, npr. okoljevarstvenih organizacij. Na neki način sledi t.i. »imisijskemu principu « vplivov na sosednja zemljišča ter sili k dogovarjanju s ciljem nevtralizacije ${ }^{\mathbf{4 2}}$ negativnih učinkov na tretje osebe, ki so prizadete. Ne dopušča pa situacije, v kateri bi sodišče postalo forum za konfrontacijo o nacionalnih političnih (npr. okoljevarstvenih) vprašanjih.

Ne glede na to, da se praviloma strinja z argumenti državne ravni in intenzivneje nadzoruje občinske oblasti, pa po drugi strani odločitve na podlagi ZUreP-1 kažejo interes sodišča, da si pridrži možnost nadzora nad »dogovori interesnih skupin« na državnem nivoju. Lastninsko pravico zaščiti le kot

40Primer U-I-158/93 Občina Velenje je $v$ ureditvenem načrtu za določen objekt prepovedala prodajo in točenje alkoholnih pijač, čeprav je $v$ istem objektu pobudnica že imela dovoljenje za preureditev tega objekta $v$ bistro. $V$ kasnejši odločbi se sodišče bolj podrobno ukvarja $z$ vprašanjem posega $v$ lastninsko pravico, ko gre za lastnika zemljišča pred cerkvijo, ki postane po PUP-u odprt prostor - zadeva: U-I-6/02. Tudi $v$ tem primeru sodišče ne ugotovi posega $v$ lastninsko pravico in se ne ukvarja $z$ vprašanjem zmanjšane vrednosti te nepremičnine. V primeru U-I-71/99 ureditvenega načrta IZ 9/5 bolnica pa ustavno sodišče oblikuje distinkcijo med pogoji za oblikovanje in rabe posameznih objektov in aktom, ki ureja namembnost prostora. Sodišče potegne zelo nenavadno ločnico med primeroma, ko se spremeni namembnost stanovanjskega objekta $v$ pastoralni objekt in ko se $v$ istem odloku predvidi rušenje kozolca. $V$ prvem primeru je to nedopustno, ker načrtovalec nima pooblastila spreminjati namembnosti obstoječega objekta. Med tem, ko so $v$ okviru iste namembnosti predvideni posegi, za katere je potrebno pridobiti individualne upravne akte, je to dopustno. Skratka sprememba šole $v$ cerkev ni načrtovanje, medtem ko rušitev hleva je.

$41 S$ tem sodišče implicitno soglaša s tezo, da gre za specifično lastninsko upravičenje.

42Nevtralizacija negativnih vplivov na tretje je tudi ekonomsko gledano instrument korekcije delovanja trga 


\section{Marko Starman}

upravičeno pričakovanje. Večino posegov $v$ lastninsko pravico sodišče dopušča. ${ }^{\mathbf{4 3}}$

Posebno pozornost posveča okoljskim ${ }^{\mathbf{4 4}}$ vprašanjem ter z zahtevami po strokovni transparentnosti, razgrnitvah in javnih obravnavah spodbuja politično odgovornost nosilcev javnih pooblastil nasploh. Čeprav standardi, ki jih je na tem področju uveljavilo sodišče, niso strogi, lahko rečemo, da sodišče prispeva h korekciji demokratičnega procesa.

\section{Zaključek}

Čeprav je ustavno sodišče le eden od akterjev v pravno-političnem procesu prostorskega načrtovanja in urejanja prostora $\vee$ praksi, je prav to področje tisto, ki razkriva večplastnost prostorskega načrtovanja samega ter vloge ustavnega sodišča $v$ demokratičnem procesu in sistemu delitve oblasti. Če izhajamo iz zastavljenih tez, je najverjetnejša prav kombinacija vseh treh. V začetnem obdobju je sodišče predvsem nadzorovalo postopek prostorskega načrtovanja na občinskem nivoju in le na tem nivoju posegalo $v$ dogovore interesnih skupin. Razveljavljalo je plane praviloma zaradi postopkovnih kršitev. Sčasoma je zaradi razpršenih interesov in vedno intenzivnejših konfliktnih situacij izgubljalo avtoriteto, saj se odločbe niso izvrševale in je tudi vlada selektivno izpodbijala prostorske akte lokalnih skupnosti. Odločba StanežičeVižmarje vsekakor predstavlja prelomno odločitev, kjer je sodišče nesporno znatno spodbudilo vlado, da zaključi postopek reforme prostorske zakonodaje in postavilo zakonodajalca pred izvršeno dejstvo razveljavitve. S tem aktom je utrdilo svojo avtoriteto ter okrepilo vlogo centralne predvsem izvršilne oblasti. Nadaljnji razvoj sodne intervencije $\vee$ prostorsko načrtovanje še ni jasno začrtan. Ali bo sodišče $v$ novi sestavi morda bolj vsebinsko pristopalo $k$ vprašanjem, povezanim s prostorskim načrtovanjem (npr. varstvo okolja), in s tem enakomerno nadzorovalo tako državne kot lokalne oblasti, bo pokazal čas.

43 Ostali posegi v lastninsko pravico, ki imajo dolgoročne učinke v javnem interesu, so upravičeni. To je moč razumeti v duhu Rawlsove teorije pravičnosti, saj je javni interes tudi v interesu tistega, ki je kratkoročno neposredno prizadet, ali le na "neobčutljivost « tranzicijskih sodnikov na lastninsko pravico.

44 Okolje je, ekonomsko gledano, javno dobro brez učinkovite interesne skupine, zato je javnopravna zaščita nujna. 


\section{Marko Starman \\ Prostorsko načrtovanje na ustavnem sodišču}

Mag. Marko Starman je po študiju na Pravni fakulteti v Ljubljani in pravni fakulteti na čikaški univerzi, opravil pripravništvo v letu 1997 na Višjem sodišču v Kopru in v odvetniški pisarni Starman-Velkaverh v Kopru. Maja 1998 se je kot svetovalec vlade zaposlil v Uradu Predsednika Vlade RS, kjer je v kabinetu podpredsednika vlade delal kot sekretar vladne komisije za preprečevanje oškodovanja družbenega in državnega premoženja ter zaščito javnega interesa ter na področju zunanjih in ustavnopravnih zadev. Opravljal je funkcijo državnega sekretarja na Ministrstvu za pravosodje RS od maja 2000 do decembra 2004, na Ministrstvu za okolje in prostor RS od decembra 2004 do marca 2007 in na Službi Vlade RS za lokalno samoupravo in regionalno politiko od marca 2007 do oktobra 2008. Od leta 2005 do 2007 je bil predsednik nadzornega sveta Luke Koper, d.d. in Infre d.o.o.. ter član Sveta Javnega podjetja Kobilarne Lipica. V letu 2000 in 2001 je bil član upravnega odbora Znanstveno raziskovalnega središča Republike Slovenije $v$ Kopru. Od leta 1999 je asistent na Fakulteti za upravo pri predmetih Uvod $v$ javno upravo in Lokalna samouprava.

\section{Literatura in viri}

- $\quad$ Craig, De B. (1998): "EU LAW, text, cases and materials" second edition, Oxford.

- Cooter, U. (1998): "Law and Economics", Oxford.

- Cole, Daniel H. (1999): „New forms of private property: Property rights in environmental goods « Indiana University School of Law. Indiana.

- $\quad$ Dukeminier, J., Krier, J. (1993): »Property« Little, Brown \& Company. London.

- Inman, R. P., Bridges, R. (1999): „Federalism«. University of Pennsylvania.

- $\quad$ Richard, P. (1992): "Economic analysis of Law". Boston, Toronto, London.

- Walter, B. (1982): "Judicial Rewiew and Rights and Law of nature» in The Supreme Court Review, Chicago.

- Towards R.H. (2007): Juristocracy: The Origins and Consequences of the New Constitutionalism, First Harvard University Press. Boston.

- $\quad$ Coase, R.H. (1988): The Firm the Market and the Law. Chicago, London.

- $\quad$ Fischel, W. A. (1985): The economics of zoning laws. The Johns Hopkins University Press.

- F.R.R. The Establishment of Constitutional Courts: A Study of 128 Democratic Constitutions.

- Marciano, A., Josselin, J. (2002): The Economic of Harmonizing European Law. University of Corisca-Pascal Paoli, France.

- T.G. Judicial Review in New Democracies: Constitutional Courts in Asian Cases, Cambridge University Press, 2003 


\section{SUMMARY}

\section{ZONING REGULATION AND PRACTICES ON THE CONSTITUTIONAL COURT - ECONOMIC ANALYSIS}

The Constitutional Court repealed the entire legislative regulation on spatial planning with its decision at the beginning of year 2002. To analyse the constitutional court's motives in such a judicially activist decision it is necessary to look carefully first at nature of the zoning regulation and practices and secondly at the role of the constitutional court in the structure of the constitution. To shade some light on such a complex process as spatial planning certainly is helpful to use different methodological tools. Case study and the conceptual framework laid down by the constitutional court itself covers only one of the aspects. Another one can be provided by the economic analysis of law. The economic analysis provides useful methodological assistance in understanding the court's decision and other factors in the procedure of spatial planning and management.

Spatial planning has become, much more than in the past, a legal category where the appropriate distribution of authority between the various branches of powers and the state and local community is essential for the system to work. It is clear that spatial planning is more than a legal phenomenon, it is above all a political process with significant economic implications. Understanding who manages the process is thus essential for understanding spatial planning. Therefore, the basic empirical question is in whose interest the decisions are made, how the decisions are made and, last but not least, what effects do they have on the community.

The greater the response of the political process to the preferences of those directly involved the more democratic the process is. It is empirically proven that the smaller communities show a greater expression of the will of the majority which on the one hand means a greater economic effectiveness and, on the other hand, a danger of influencing the vital interests of the politically (marginal) groups.

In the case of larger units of public authority (as the state level), there is a danger that narrowed and well-organised interest groups shall prevail and thus the interests of a wider community are annulled. They have an influence in the process due to the high transactional costs including the expert bases, public exhibitions, agreements with the owners, etc, and 
Marko Starman

Prostorsko načrtovanje na ustavnem sodišču

others, to name a few: planners, autonomous interests of the state or local bureaucracy, etc.

The Slovenian practice seen trough the methodological framework of economic analysis of the law shows that urbanisation usually follows the interests of the cartelized interests of big construction companies that controls the property rights of the land. Competition between investors in the same area is simply not possible. It is obvious that public service which is provided in the zoning regulation is missing. Zoning regulation is by its nature intended as a sort of distribution of opportunities on the land in public interest. This is possible only if it is done in advance on an abstract level, transparently, regardless of the individual interests of the stakeholders, which are already in control of the property interests. It is easy to explain why the integrity and the long run planning are so important.

Why so? Looking at it from the economic point of view land use regulation by local or national authorities is a distribution of the scope of property rights on a specific territory that largely defines the value of that property. The economic land value is a discounted value of its future yields. Defining the land use means implementing a regulatory function of the public authority. This function is by definition a "monopoly". Exclusively these authorities can perform it. In short space is a natural monopoly and is therefore viewed as public good. Spatial planning is therefore justified solely as public service.

Our practice of spatial planning at the municipality levels follows the general pattern, due to the absence of comprehensive planning. Therefore, the main operation is to acquire real estate which land use will change in such a way that its value will grow. If only land speculation is involved it is not economically harmful on its own as the risk is borne by the speculator. While the situation is different if a connection exists between the potential beneficiary of the land and the authority that sets the land use. The levels mutual influence or involvement can be different. In any case, this involves a kind of trading with the inside information, indeed "insider trading".

Following the analysis of the nature of land use regulation or spatial planning process we can see that there is acute problem of lack of transparency. The issue is how to change the status quo. Could the constitutional court by its own actions be the instrument of change? Could it function as a tool of transition from a practice that has its roots in the authoritarian past? 
Even though the constitutional court is only one of the actors in the legal and political process of spatial planning and land management in practice, it is this field which unfolds the multi-layered nature of spatial planning itself and the role of the constitutional court within the democratic process in the system of division of powers. The fact is that property rights and the conflicting interest involved are much more defined in the market economy than in the previous political system, which was based on centralized planning. Even though there has been almost 20 years since the constitutional changes the zoning regulation in force in 2002 was adopted in the previous system.

That was one of the reasons that the constitutional court used to strike down all the relevant laws in this area. What was actually going on the constitutional court before the decision U-I-227/00 - Stanežiče-Vižmarje of 2002 and how did the Court react later in more recent decisions? Three different possible explanations are developed trough case study and economic analysis of the law.

First, the Court did lack instruments with which it could efficiently provide legality in the legal area. The transaction cost of ensuring legality became so high that it out-weighted the benefit of the court's actions. The decision is, therefore, rational and in line with the function of the constitutional - judicial authority.

Secondly, the Court is in the field of providing legality and constitutionality the only responsible court and therefore has monopolistic jurisdiction. The judiciary power as an institution maximises its benefits, which also includes authority. With this decision it enhanced its position in the system of division of authority - with the annulment directly and the declaration of why the system is unconstitutional indirectly.

Thirdly the court is a means of "interest groups organised at the national level" or an instrument of centralisation. With the decision it dismissed with the last obstacle, i.e. the holders of dispersed policy, namely the municipal authorities and individual interests of the members of the parliament. The chances that the legislative proposal of the government would be adopted (which was at the time already in the parliamentary procedure) have substantially increased, because a threat of a legislative void existed and therefore the inability of making and changing spatial plans.

If we derive from the set theses the combination of all three is most probable. In the initial phase the Court mainly supervised the process of 
spatial planning at the municipality level and interfered with the agreements of the interest groups at this level. It usually annulled the plans due to the violations of the procedure. Due to the disbursed interests and more intense conflict situations it gradually lost its authority as the decisions were not executed and the government also selectively contested the acts of the local communities. The situation pushed the Court in a defensive position.

The Stanežiče-Vižmarje Decision is most definitely a turning point as the Court encouraged the government to speed up the procedures of reforming the spatial legislature and forced the legislator to act with the act of annulment. It strengthened its authority with this act. The following development of the intervention in spatial planning is not so vividly set. Only time will tell whether the Court will, in its new constitution, take a substantive approach to the issues of spatial planning (e.g. environment protection).

The development of legal doctrines in an area as zoning regulation and practices tells a great deal of the struggle between branches of government and the nature of self-government on the local level. The analysis that goes beyond wordings of the judicial decisions and legal norms shows again and again that law in action is much more telling than law on books. 